\title{
Tetraeffective causes, mortacauses, and vitacauses of mortality and survivorship
}

\author{
Michael Epelbaum
}

Every tetraeffective cause of mortality and survivorship negatively and positively affects mortality and negatively and positively affects survivorship. There is previous evidence of tetraeffective causes of mortality and survivorship, and strong rationales suggest that every cause of mortality and survivorship is tetraeffective. Here I elucidate and explain that every tetraeffective cause of mortality and survivorship combines corresponding at least one cause-specific mortacause and at least one cause-specific vitacause; "mortacause" refers here to a cause-specific component that positively affects mortality and negatively affects survivorship, and "vitacause" refers to a cause-specific component that positively affects survivorship and negatively affects mortality. I show tetraeffective causes, mortacauses, and vitacauses in results of multivariable regression analyses of effects of age, lifespan, contemporary aggregate size, lifespan aggregate size, and historical time on humans' and medflies' mortality and survivorship. In these analyses I specify tetraeffective causes, mortacauses, and vitacauses with $\operatorname{sign}\left(\beta_{1}\right)=-\operatorname{sign}\left(\beta_{2}\right)$, where respective corresponding $\beta_{1}$ and $\beta_{2}$ denote respective first and second variablespecific regression coefficients. Thus tetraeffective causes, mortacauses, and vitacauses of mortality and survivorship are hereby defined, identified, named, recognized, elucidated, conceptualized, specified, explained, and demonstrated.

Wildfires are tetraeffective causes that negatively and positively affect mortality and survivorship of plants and animals ${ }^{1}$. There is also ample evidence of iatrogenic effects on mortality and survivorship ${ }^{2,3}$, including, for example, iatrogenic effects of surgery ${ }^{4}$ and pharmacologic medication (e.g., antibiotics ${ }^{5,6}$ ). In its totality, previous research on social, economic, cultural, or political causes of humans' mortality and survivorship shows that each of these kinds of causes is tetraeffective ${ }^{7-21}$. Additionally, Strehler-Mildvan correlations $^{22-29}$, compensations ${ }^{27,28,30,31}$, and hysteresis or delays ${ }^{32-34}$ in effects of age on mortality and survivorship show that age is a tetraeffective cause of mortality and survivorship. These considerations show that there is evidence of tetraeffective causes of mortality and survivorship. However, until now, tetraeffective causes of mortality and survivorship have remained undefined, unidentified, unnamed, unrecognized, unclear, misconceived, unspecified, and unexplained.

Here I elucidate and explain that every tetraeffective cause of mortality and survivorship combines corresponding at least one cause-specific mortacause and at least one cause-specific vitacause. Fig. 1 depicts the causal structure of a tetraeffective cause $X$ that affects mortality $M$ and survivorship $S$ through the combined positive effects of an $X$-specific mortacause $X m$ on mortality $M$, negative effects of an $X$-specific mortacause $X m$ on survivorship $S$, negative effects of an $X$-specific vitacause $X v$ on mortality $M$, and positive effects of an $X$-specific vitacause $X v$ on survivorship $S$ (e.g., illustrating that an increasing $X m$ leads to increasing $M$ and decreasing $S$ and illustrating that an increasing $X v$ leads to increasing $S$ and decreasing $M$ ). Tetraeffective causes could have diverse causal structures; for example, while Fig. 1 presents a causal structure of a tetraeffective 
cause with one mortacause and one vitacause, Fig. 2 presents a causal structure of a tetraeffective cause with more than one mortacause and more than one vitacause. The

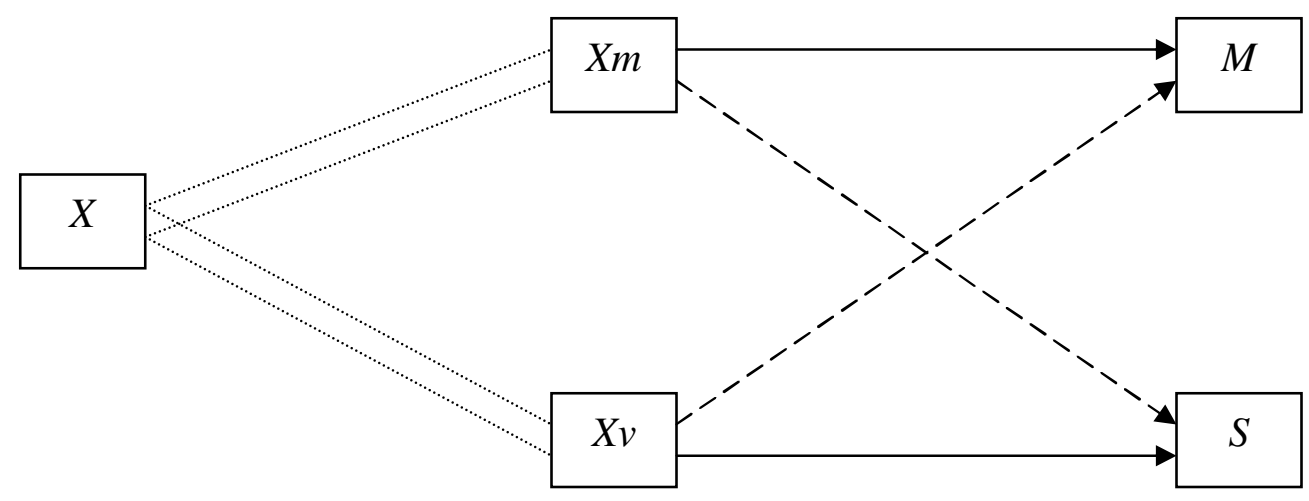

Figure 1: A causal structure of effects one mortacause and one vitacause on mortality and survivorship. $X$ denotes a tetraeffective cause of mortality $M$ and survivorship $S, X m$ denotes an $X$-specific mortacause, $X v$ denotes an $X$-specific vitacause, double dotted lines denote that $X m$ and $X v$ are $X$-specific, arrow $\rightarrow$ denotes positive effects, and arrow ----> denotes negative effects.

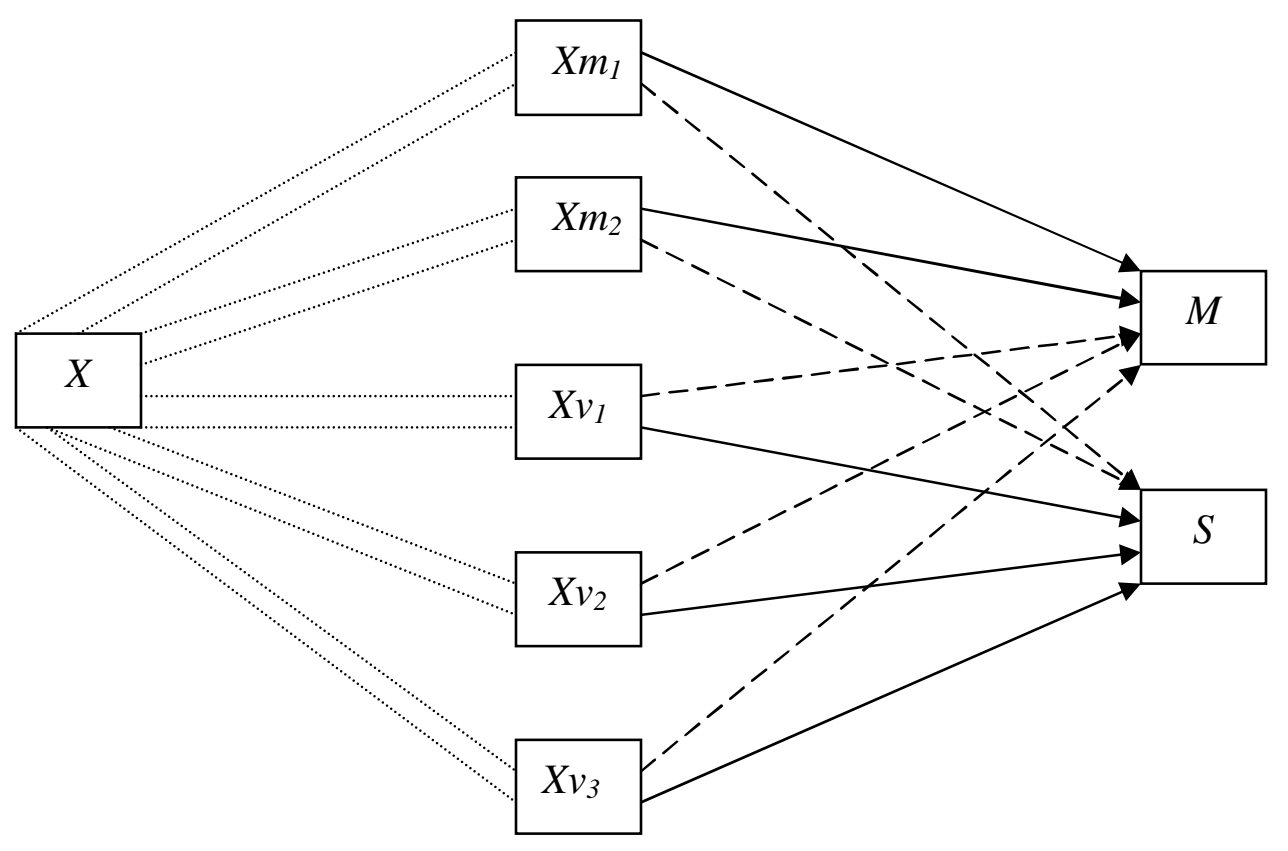

Figure 2: A causal structure of effects of two mortacauses and three vitacauses on mortality and survivorship. $X$ denotes a tetraeffective cause of mortality $M$ and survivorship $S, X m$ denotes an $X$-specific mortacause, $X v$ denotes an $X$-specific vitacause, double dotted lines denote that $X m$ and $X v$ are $X$-specific, arrow $\rightarrow$ denotes positive effects, and arrow ----> denotes negative effects. 
causal structures that are depicted in Fig. 1 and Fig. 2 are consistent with the laws of identity, noncontradiction, and excluded middle ${ }^{35-37}$. In contrast, Fig. 3 depicts the causal structure of a cause $X$ that directly negatively and positively affects mortality $M$ and directly negatively and positively affects survivorship $S$. The causal structure that is depicted in Fig. 3 is inconsistent with the laws of identity, noncontradiction, and excluded middle; moreover, the causal structure that is depicted in Fig. 3 does not validly depict the causal structure of tetraeffective causes of mortality and survivorship.

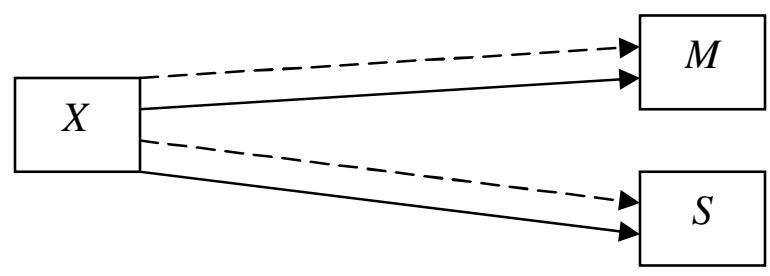

\section{Figure 3: A causal structure of direct negative and positive effects on mortality and direct negative and positive effects on survivorship. $X$ denotes a cause that directly negatively and positively affects mortality $M$ and survivorship $S$, arrow $\rightarrow$ denotes positive effects, and arrow ----> denotes negative effects.}

Mortality refers to cessation of existence, survivorship refers to continuation of existence, and that which exists or ceases to exist is an entity. An entity can be simple or complex, natural or artificial, living or non-living; a particle, droplet, cell, virus, insect, human, plant, rock, lake, mountain, planet, celestial system, universe, city, sculpture, bicycle, airplane, basketball team, nation state, language, book, or poem are some of the many examples of an entity. All previous entities existed and ceased to exist, the universe and all its present and future entities will cease to exist ${ }^{38-41}$, and continuations and cessations of existences are regulated ${ }^{42-50}$; therefore, mortality, survivorship, and their causes are regulated regulators of the existence of every entity. If every cause of mortality and survivorship is a tetraeffective cause of mortality and survivorship, then tetraeffective causes are intimately involved in the existence - and the continuation, regulation, and limitation of existence - of every entity. However, if diverse but not all causes of mortality and survivorship are tetraeffective causes of mortality and survivorship, then existence - and continuation, regulation, and limitation of existence do not consistently apply to every entity. Similarly, if no causes of mortality and survivorship are tetraeffective, then existence - and continuation, regulation, and limitation of existence - do not consistently apply to every entity. Therefore, every cause of mortality and survivorship is tetraeffective.

The total number of causes of mortality and survivorship in an hypothetical system that involves only tetraeffective causes in the regulated regulations and limitations of existence of all entities is smaller than the total number of causes of mortality and survivorship in an hypothetical system that excludes tetraeffective causes of mortality and survivorship from the regulated regulations and limitations of existence of all entities. Therefore, a system that involves tetraeffective causes of mortality and survivorship in the regulated regulations and limitations of existence of all entities is 
more parsimonious than a corresponding system that excludes tetraeffective causes of mortality and survivorship. This parsimony provides an additional rationale for the universality of tetraeffective causes of mortality and survivorship. Furthermore, symbioses between corresponding at least one cause-specific mortacause and at least one cause-specific vitacause of every tetraeffective cause of mortality and survivorship are illustrated by the observation that any positive effect of age on mortality and any negative effect of age on survivorship require entities of ages greater than zero, and any entity of age greater than zero requires corresponding negative effects of age on mortality and positive effects of age on survivorship; these symbioses and requirements imply that effects of age on mortality and survivorship are tetraeffective, further implying that age is a tetraeffective cause of mortality and survivorship. Similar symbioses, requirements, and implications apply to every entity and every cause of mortality and survivorship. These considerations provide additional rationales for the universality of tetraeffective causes of mortality and survivorship.

Extensive and longstanding considerations of oppositions in religion and philosophy ${ }^{35,36,51-63}$, quantum theory ${ }^{64,65}$, structuralism ${ }^{66-68}$, biology ${ }^{69-71}$, and art ${ }^{72-77}$ imply that every mortacause is opposed by - and opposes - a corresponding at least one vitacause. These considerations also imply that every vitacause is opposed by - and opposes - a corresponding at least one mortacause. Additionally, these considerations imply that every tetraeffective cause opposes - and is opposed by - another tetraeffective cause. However, if every cause of mortality and survivorship is not tetraeffective (i.e., if tetraeffective causes of mortality and survivorship do not exist) then at least some causes of mortality are not opposed and at least some causes of survivorship are not opposed, such that these absences of oppositions violate the requisites of opposition. Moreover, if every cause of mortality and survivorship is not tetraeffective then at least some entities do not cease to exist, violating the law of cessation of existence of every entity. Therefore, and in consistency with ample previous scientific consideration of intrinsic and extrinsic causes of mortality and survivorship ${ }^{25,27,31,78-91}$, as well as in consistency with previous considerations of essential and coincidental properties ${ }^{35,92}$ - corresponding at least one mortacause and at least one vitacause must be intrinsic to every cause of mortality and survivorship and, therefore, every cause of mortality and survivorship is tetraeffective.

Components of tetraeffective causes of mortality and survivorship can be hidden (e.g., these components can be unknown, unobserved, ignored, or misconceived). However, the hiddenness of at least one mortacause of a tetraeffective cause of mortality and survivorship does not imply the following: (i) the at least one mortacause does not exist, and (ii) the cause is not tetraeffective. Similarly, the hiddenness of at least one vitacause of a tetraeffective cause of mortality and survivorship does not imply the following: (i) the at least one vitacause does not exist, and (ii) the cause is not tetraeffective. Therefore, it is invalid to conclude that a cause - e.g., every cause, any cause, a specific cause - of mortality and survivorship is not a tetraeffective cause. Furthermore, the continuation of an entity's existence does not mean that respective causes of the cessation of this entity's existence do not affect this entity's existence; similarly, the cessation of an entity's existence does not mean that respective causes of the continuation of this entity's existence do not affect this entity's cessation of existence. These considerations show that the universality of tetraeffective causes of mortality and survivorship is undeniable. 
Diverse cultures, religions, philosophies, and scientific investigations consider effects of damage, frailty, disease, injury, waste, harm, poison, thanatos, destroyer of worlds, nuclear holocaust, global warming, poverty, injustice, or similar phenomena on mortality and survivorship ${ }^{27,28,60-63,93-108}$. Similarly, diverse cultures, religions, philosophies, and scientific investigations consider effects of vitality, conatus, élan vital, self-preservation, repair, redundancy, defense, nutrition, elixirs, or similar phenomena on mortality and survivorship ${ }^{22,27,28,31,35,60,61,63,83,109-122}$. The universality of tetraeffective causes of mortality and survivorship means that it is useful, practical, moral, and ethical to assume that every vitality is accompanied by an opposite frailty and vice versa, every damage is accompanied by an opposite repair and vice versa, every injury or disease is accompanied by an opposite remedy and vice versa, and so on; further implying that it is invalid, impractical, immoral, unethical, and not useful to assume that positive affects on mortality and negative effects on survivorship are unopposed; further implying that it is invalid, impractical, immoral, unethical, and not useful to assume that negative effects on mortality and positive effects on survivorship are unopposed. Thus, utilitarian, practical, moral, and ethical considerations provide additional rationales for the universality of tetraeffective causes of mortality and survivorship.

Previous scientific research does not provide mathematical specifications of tetraeffective causes, mortacauses, and vitacauses of mortality and survivorship. Moreover, previous scientific research does not provide evidence of mortacauses and vitacauses of tetraeffective causes of mortality and survivorship. Here I specify tetraeffective causes, mortacauses, and vitacauses, and I analyze humans' and medflies' mortality and survivorship in search of evidence of tetraeffective causes, mortacauses, and vitacauses.

\section{Methods}

A previous investigation presents multivariable regression analyses of (1) 188,087 weighted cases with $79,164,608$ events of death or survival of all individuals that were born in Sweden in decennial years 1760 - 1930 and died between 1760 and 2008, and (2) 50,716 weighted cases with 2,211,782 events of death or survival of caged Mediterranean fruit flies, Ceratitis capitata, commonly known as medflies ${ }^{123}$. These analyses employ AIC and BIC information criteria in tests of the following multivariable individual-level longitudinal limited powered polynomials binary random-effects regression model:

$$
\eta_{i j}=\beta_{0}+\sum_{q=1}^{n} \sum_{k=1}^{r_{q}}\left[\beta_{q k}\left\{\left(X_{q i j}\right)^{p_{q}}\right\}^{k}\right]+\sum_{v=1}^{u}\left(\beta_{v} W_{v i j}\right)+\xi_{i j} \text {, such that } P\left(Y_{i j}\right)=f\left(\eta_{i j}\right) \text {, }
$$

where $Y_{i j}$ denotes mortality $M_{i j}$ or survivorship $S_{i j}$ of an individual human or medfly $i$ that continues to exist (i.e., $M_{i j}=0$ and $S_{i j}=1$ ) or ceases to exist (i.e., $M_{i j}=1$ and $S_{i j}=0$ ) at humans' year $j$ or medflies' day $j, P\left(Y_{i j}\right)$ denotes the probability of mortality (i.e., $\left.P\left(M_{i j}\right)\right)$ or the probability of survivorship (i.e., $\left.P\left(S_{i j}\right)\right)$ of individual $i$ at observation $j, f\left(\eta_{i j}\right)$ is a link function that denotes a transformation of $\eta_{i j}$ (e.g., a logit transformation $P\left(Y_{i j}\right)=$ $\left.\exp \left(\eta_{i j}\right) /\left\{1+\exp \left(\eta_{i j}\right)\right\}\right), \boldsymbol{\beta}$ denote regression coefficients $\beta, \boldsymbol{X}_{\boldsymbol{q}}$ denote ordinal or higherlevel variables $X$, and $\boldsymbol{W}_{\boldsymbol{v}}$ denote categorical variables $W$. The specific $\boldsymbol{X}_{\boldsymbol{q}}$ variables in this investigation are: $X=A$ denotes humans' or medflies' age, $X=L$ denotes humans' or medflies' lifespan, $X=C$ denotes humans' or medflies' contemporary aggregate size (i.e., this size refers to the number of individuals whose age, sex, and location in time or space are identical to those of the criterion individual), $X=\Lambda$ denotes humans' or 
medflies' lifespan aggregate size (i.e., this size refers to the number of individuals whose lifespan, age, sex, and location in time or space are identical to those of the criterion individual), and $X=H$ denotes humans' historical time (i.e., a specific year). The specific $\boldsymbol{W}_{\boldsymbol{v}}$ variables in this investigation are: $W=F$ denotes being female in reference to humans' or medflies' sex, and $W=Q$ denotes medflies' respective cages. Coefficients $q$ denote sequential indicators of $n$ distinct variables $X, p_{q}$ denotes a power coefficient of variable $X_{q}, k$ are sequential indicators of the $r_{q}$ polynomial length of variable $X_{q}$. Coefficients $v$ denote sequential indicators of $u$ distinct variables $W$, and each $\xi_{i j}$ denotes a random-effects coefficient corresponding to individual $i$ at observation $j$. The previous investigation provides further information on these data and regression analyses ${ }^{123}$.

A regression coefficient $\beta_{1}$ denotes here the first regression coefficient that applies to an ordinal or higher level variable $X$ in Model 1, and a regression coefficient $\beta_{2}$ denotes here the second regression coefficient that applies to this variable $X$ in Model 1 , allowing for additional - i.e., third or more - regression coefficients for this variable $X$. Relationship $\operatorname{sign}\left(\beta_{1}\right)=-\operatorname{sign}\left(\beta_{2}\right)$ for an ordinal or higher level variable $X$ in Model 1 indicates here that variable $X$ is a tetraeffective cause of mortality and survivorship. Relationships $\beta_{1}>0$ and $\beta_{2}<0$ at $Y=M$ and relationships $\beta_{1}<0$ and $\beta_{2}>0$ at $Y=S$ for a variable $X$ in Model 1 indicate here that $\beta_{1}$ is an indicator of effects of an $X$-specific mortacause, further indicating that $\beta_{2}$ is an indicator of effects of an $X$-specific vitacause. Relationships $\beta_{1}<0$ and $\beta_{2}>0$ at $Y=M$ and relationships $\beta_{1}>0$ and $\beta_{2}<0$ at $Y=S$ for a variable $X$ in Model 1 indicate here that $\beta_{1}$ is an indicator of effects of an $X$-specific vitacause, further indicating that $\beta_{2}$ is an indicator of effects of an $X$-specific mortacause. Each additional respective coefficient $\beta$ for a variable $X$ in Model 1 indicates here another respective $X$-specific mortacause or vitacause. Such indications apply to every variable $X$ in Model 1. Respective $X$-specific multivariable regression coefficients $\beta_{1}$ and $\beta_{2}$ denote here the respective multivariable regression coefficients for the following variables $X$ in Model 1: Humans' and medflies' age $(X=A)$, lifespan $(X=L)$, contemporary aggregate size $(X=C)$, and lifespan aggregate size $(X=\Lambda)$ as well as humans' historical time $(X=$ $H)$.

\section{Results}

Table 1 reveals $\operatorname{sign}\left(\beta_{1}\right)=-\operatorname{sign}\left(\beta_{2}\right)$ in the multivariable regression analyses of effects age, lifespan, contemporary aggregate size, or lifespan aggregate size on humans' and medflies' mortality and survivorship, as well as in the multivariable regression analyses of effects of historical time on humans' mortality and survivorship. Relationships $\operatorname{sign}\left(\beta_{1}\right)=-\operatorname{sign}\left(\beta_{2}\right)$ in Table 1 thus respectively indicate here that humans' and medflies' age, lifespan, contemporary aggregate size, and lifespan aggregate size are respective tetraeffective causes of respective humans' and medflies' mortality and survivorship. Relationships $\operatorname{sign}\left(\beta_{1}\right)=-\operatorname{sign}\left(\beta_{2}\right)$ in Table 1 also indicate that humans' historical time is a tetraeffective cause of humans' mortality and survivorship. Additionally, Table 1 reveals relationships $\beta_{1}<0$ and $\beta_{2}>0$ at $Y=M$, and Table 1 also reveals relationships $\beta_{1}$ $>0$ and $\beta_{2}<0$ at $Y=S$; further revealing here that respective $\beta_{1}$ indicate effects of respective $X$-specific vitacauses - and further revealing here that respective $\beta_{2}$ indicate effects of respective $X$-specific mortacauses - on respective humans' and medflies' mortality and survivorship, where $X$ denote humans' and medflies' age $(X=C)$ and lifespan $(X=L)$ and where $X$ denote medflies' contemporary aggregate size $(X=C)$ and 
lifespan aggregate size $(X=\Lambda)$. Moreover, Table 1 reveals relationships $\beta_{1}>0$ and $\beta_{2}<$ 0 at $Y=M$, and Table 1 also reveals relationships $\beta_{1}<0$ and $\beta_{2}>0$ at $Y=S$; further revealing here that respective $\beta_{1}$ indicate effects of respective $X$-specific mortacauses and further revealing that respective $\beta_{2}$ indicate effects of respective $\mathrm{X}$-specific vitacauses - on humans' mortality and survivorship, where $X$ denote humans' contemporary aggregate size $(X=C)$ and lifespan aggregate size $(X=\Lambda)$. Furthermore, Table 1 reveals relationships $\beta_{1}<0, \beta_{2}>0$, and $\beta_{3}<0$ at $Y=M$, and Table 1 also reveals relationships $\beta_{1}>0$ and $\beta_{2}<0$, and $\beta_{3}>0$ at $Y=S$; further revealing here that respective $\beta_{1}$ and $\beta_{3}$ indicate effects of respective humans' historical-time-specific vitacauses - and respective $\beta_{2}$ indicates effects of humans' historical-time-specific mortacause - on humans' mortality and survivorship.

Table 1. Values of $\boldsymbol{\beta}_{1}$ and $\boldsymbol{\beta}_{2}$ in best-fitting Models 1. $Y=M$ denotes mortality, $Y=S$ denotes survivorship, $X=A$ denotes age, $X=L$ denotes lifespan, $X=C$ denotes contemporary aggregate size, $X=\Lambda$ denotes lifespan aggregate size, and $X=H$ denotes historical time. Respective low and high $\beta_{1}$ and $\beta_{2}$ values respectively denote low and high values of these coefficients at respective $95 \%$ confidence intervals. $\beta_{3}=-7.97 \mathrm{E}-10$, low $\beta_{3}=-8.12 \mathrm{E}-10$, high $\beta_{3}=-7.82 \mathrm{E}-10$ at humans' $X=H$ and $Y=M$. $\beta_{3}=7.97 \mathrm{E}-10$, low $\beta_{3}=7.82 \mathrm{E}-10$, high $\beta_{3}=8.12 \mathrm{E}-10$ at humans' $X=H$ and $Y=S$. Adapted from a previous investigation $^{123}$

\begin{tabular}{|l|c|c|c|c|c|c|c|c|c|}
\hline entities & $\boldsymbol{Y}$ & $\boldsymbol{X}$ & $\boldsymbol{p}$ & $\boldsymbol{\beta}_{\boldsymbol{1}}$ & $\boldsymbol{\beta}_{\boldsymbol{2}}$ & low $\boldsymbol{\beta}_{\boldsymbol{1}}$ & high $\boldsymbol{\beta}_{\boldsymbol{1}}$ & low $\boldsymbol{\beta}_{\boldsymbol{2}}$ & high $\boldsymbol{\beta}_{\boldsymbol{2}}$ \\
\hline humans & $\mathrm{M}$ & $\mathrm{A}$ & 0.16 & -1074.55 & 546.12 & -1076.92 & -1072.19 & 544.92 & 547.32 \\
\hline humans & $\mathrm{S}$ & $\mathrm{A}$ & 0.16 & 1074.55 & -546.12 & 1072.19 & 1076.92 & -547.32 & -544.92 \\
\hline medflies & $\mathrm{M}$ & $\mathrm{A}$ & 0.13 & -2648.52 & 1295.76 & -2681.20 & -2615.85 & 1279.76 & 1311.76 \\
\hline medflies & $\mathrm{S}$ & $\mathrm{A}$ & 0.16 & 1402.49 & -706.62 & 1373.72 & 1431.25 & -721.29 & -691.95 \\
\hline humans & $\mathrm{M}$ & $\mathrm{L}$ & 0.88 & -17.12 & 0.10 & -17.16 & -17.08 & 0.10 & 0.10 \\
\hline humans & $\mathrm{S}$ & $\mathrm{L}$ & 0.88 & 17.12 & -0.10 & 17.08 & 17.16 & -0.10 & -0.10 \\
\hline medflies & $\mathrm{M}$ & $\mathrm{L}$ & 0.98 & -16.67 & 0.09 & -16.88 & -16.46 & 0.09 & 0.10 \\
\hline medflies & $\mathrm{S}$ & $\mathrm{L}$ & 0.94 & 19.24 & -0.12 & 18.82 & 19.65 & -0.12 & -0.11 \\
\hline humans & $\mathrm{M}$ & $\mathrm{C}$ & 0.75 & 0.00623 & $-4.39 \mathrm{E}-07$ & 0.00619 & 0.00627 & $-4.46 \mathrm{E}-07$ & $-4.33 \mathrm{E}-07$ \\
\hline humans & $\mathrm{S}$ & $\mathrm{C}$ & 0.75 & -0.00623 & $4.39 \mathrm{E}-07$ & -0.00627 & -0.00619 & $4.33 \mathrm{E}-07$ & $4.46 \mathrm{E}-07$ \\
\hline medflies & $\mathrm{M}$ & $\mathrm{C}$ & 1.02 & -0.00632 & $6.85 \mathrm{E}-07$ & -0.00652 & -0.00612 & $6.54 \mathrm{E}-07$ & $7.15 \mathrm{E}-07$ \\
\hline medflies & $\mathrm{S}$ & $\mathrm{C}$ & 1.02 & 0.00407 & $-4.03 \mathrm{E}-07$ & 0.00388 & 0.00427 & $-4.32 \mathrm{E}-07$ & $-3.74 \mathrm{E}-07$ \\
\hline humans & $\mathrm{M}$ & $\Lambda$ & 0.3 & 6.18689 & -0.34869 & 6.16888 & 6.20490 & -0.34969 & -0.34768 \\
\hline humans & $\mathrm{S}$ & $\Lambda$ & 0.3 & -6.18689 & 0.348686 & -6.20490 & -6.16888 & 0.34768 & 0.34969 \\
\hline medflies & $\mathrm{M}$ & $\Lambda$ & 0.95 & -0.09025 & 0.000263 & -0.09327 & -0.08723 & 0.00025 & 0.00027 \\
\hline medflies & $\mathrm{S}$ & $\Lambda$ & 0.88 & 0.11285 & -0.00049 & 0.10723 & 0.11846 & -0.00052 & -0.00046 \\
\hline humans & $\mathrm{M}$ & $\mathrm{H}$ & 1.41 & $-7.84 \mathrm{E}-03$ & $1.92 \mathrm{E}-06$ & $-7.91 \mathrm{E}-03$ & $-7.77 \mathrm{E}-03$ & $1.86 \mathrm{E}-06$ & $1.97 \mathrm{E}-06$ \\
\hline humans & $\mathrm{S}$ & $\mathrm{H}$ & 1.41 & $7.84 \mathrm{E}-03$ & $-1.92 \mathrm{E}-06$ & $7.77 \mathrm{E}-03$ & $7.91 \mathrm{E}-03$ & $-1.97 \mathrm{E}-06$ & $-1.86 \mathrm{E}-06$ \\
\hline
\end{tabular}




\section{Discussion}

The foregoing considerations provide identifications, names, recognitions, elucidations, conceptions, specifications, explanations, and demonstrations of tetraeffective causes, mortacauses, and vitacauses of mortality and survivorship. These considerations of tetraeffective causes of mortality and survivorship usefully elucidate - and deepen the consideration of, and expand the scope of scientific research on - causes of mortality and survivorship. These considerations also provide a new paradigm of causes of mortality and survivorship, and enable and promote further scientific research and practical applications $^{124,125}$. These considerations - and the methodology that is employed here and in a previous investigation ${ }^{123}$ - could thus prove to be particularly useful because scientific research on causality remains problematic and challenging ${ }^{35,126-130}$, scientific research on causes of mortality and survivorship remains particularly problematic and challenging $^{21,131-138}$, and mortality and survivorship and their interrelationships are particularly prone to elicit errors and biases ${ }^{139-144}$.

Conceptions of deep or latent structures are found in diverse fields of science and scholarship ${ }^{66,67,130,145-149}$; conceptions of mortacauses and vitacauses of tetraeffective causes of mortality and survivorship have obvious affinities with conceptions of deep or latent structures, but much remains to be learned about these affinities. Additionally, as noted, conceptions of frailty, damage, disease, injury, waste, harm, poison, thanatos, destroyer of worlds, nuclear holocaust, global warming, poverty, injustice, and related phenomena are found in diverse cultures, religions, philosophies, and scientific investigations ${ }^{27,28,60-63,93-108}$; these conceptions have obvious affinities with conceptions of mortacauses, but much remains to be learned about these affinities. As also noted, conceptions of vitality, conatus, élan vital, self-preservation, repair, redundancy, defense, nutrition, elixirs, and related phenomena are found in diverse cultures, religions, philosophies, and scientific investigations ${ }^{22,27,28,31,35,60,61,63,83,109-122}$; these conceptions have obvious affinities with conceptions of vitacauses, but much remains to be learned about these affinities. Moreover, the extensive and longstanding considerations of oppositions in religion and philosophy ${ }^{35,36,51-63}$, quantum theory ${ }^{64,65}$, structuralism $^{66-68}$, biology ${ }^{69-71}$, and art $^{72-77}$ emphasize that opposites differ with respect to specific variable or invariant characteristics (e.g., effectiveness, dominance, dynamism, intensity, potency, force, and other characteristics), further emphasizing that oppositions can be variable or invariant, and further emphasizing that oppositions are somehow resolved or come to some kind of aufheben ${ }^{54,150,151}$. These considerations - and the differences and similarities among effects of age, lifespan, contemporary aggregate size, lifespan aggregate size, and historical time on mortality and survivorship of humans and medflies in this investigation - show that much remains to be learned about the modulation, functions, evolutionary contexts, and characteristics of diverse kinds of tetraeffective causes, mortacauses, and vitacauses of mortality and survivorship of diverse kinds of entities in diverse times and places.

Searches for models and laws of mortality or survivorship are longstanding and inconclusive $22,27,31,42-46,80,100-102,115,116,120,152-172$. The considerations in this article provide a foundation for a hypothetical law of tetraeffective causes of mortality and survivorship; this hypothetical law states that every cause of mortality and survivorship is a tetraeffective cause that is composed of corresponding at least one cause-specific mortacause and at least one cause-specific vitacause. Specifications $\operatorname{sign}\left(\beta_{1}\right)=-\operatorname{sign}\left(\beta_{2}\right)$ in multivariable regression models provide succinct, parsimonious, simple, and 
meaningful specifications of tetraeffective causes, mortacauses, and vitacauses of mortality and survivorship. Specifications $\operatorname{sign}\left(\beta_{1}\right)=-\operatorname{sign}\left(\beta_{2}\right)$ and the hypothetical law of tetraeffective causes of mortality and survivorship contribute to the longstanding and inconclusive searches for models and laws of mortality and survivorship. The scope of these specifications and hypothetical law can be investigated in further research on diverse kinds of tetraeffective causes, mortacauses, and vitacauses of mortality and survivorship of diverse kinds of entities in diverse times and places ${ }^{173,174}$.

\section{References}

1. Wikipedia. Wildfire. Wikipedia, the free encyclopedia http://en.wikipedia.org/wiki/. Accessed February 10 (2016).

2. Illich, I. Medical Nemesis: The Expropriation of Health. (Caler \& Boyars, 1974).

3. Wikipedia. Entry on "iatrogenesis." Wikipedia, The Free Encyclopedia http://en.wikipedia.org/wiki/. Accessed May 3 (2015).

4. Wikipedia. Entry on "Perioperative mortality." Wikipedia, The Free Encyclopedia http://en.wikipedia.org/wiki/. Accessed July 17. (2015).

5. Wikipedia. Antimicrobial resistance. Wikipedia, the free encyclopedia http://en.wikipedia.org/wiki/. Accessed December 3 (2015).

6. Wikipedia. Antibiotics. Wikipedia, the free encyclopedia http://en.wikipedia.org/wiki/. Accessed December 3 (2015).

7. Preston, S. H. Mortality Patterns In National Populations. (Academic Press, 1976).

8. Epelbaum, M. Sociomonetary patterns and specifications. Social Science Research 19, 322-347 (1990).

9. Krieger, N., Rowley, D. L., Herman, A. A., Avery, B. \& Phillips, M. T. Racism, sexism, and social class: Implications for studies of health, disease, and well-being. American Journal of Preventive Medicine 9, 82-122 (1993).

10. Wrigley, E. A., Oeppen, J. E. \& Schofield, R. S. English Population History from Family Reconstitution 1580-1937. (Cambridge University Press, 1997).

11. Lynch, J., Davey Smith, G., Harper, S., Kaplan, G. A. \& Wolfson, M. Is income inequality a determinant of population health? Part 1. A systematic review. The Milbank Quarterly 82, 5-99 (2004).

12. Smith, J. P. Unraveling the SES-health connection. Population and Development Review 30, 108-132 (2004).

13. Cutler, D. M., Deaton, A. \& Lleras-Muney, A. The determinants of mortality. Journal of Economic Perspectives 20, 97-120 (2006).

14. Krieger, N. et al. The fall and rise of US inequities in premature mortality: 19602002. PLoS Med 5, e46 (2008).

15. Riley, J. C. Low Income, Social Growth, and Good Health: A History of Twelve Countries. (University of California Press, 2008).

16. Lynch, J., Davey Smith, G., Harper, S. \& Hillemeier, M. Is income inequality a determinant of population health? Part 2. U.S. national and regional trends in income inequality and age- and cause-specific mortality. The Milbank Quarterly 82, 355-400 (2004).

17. Johansson, S. R. \& Mosk, C. Exposure, resistance, and life expectancy: Disease and death during the economic development of Japan, 1900-1960. Population Studies 41, 207-235 (1987). 
18. Mosk, C. \& Johansson, S. R. Income and mortality: Evidence from modern Japan. Population Development Review 12, 415-440 (1986).

19. Adler, N. E. et al. Socioeconomic status and health: The challenge of the gradient. American Psychologist 49, 15-24 (1994).

20. Antonovsky, A. Social class, life expectancy, and overall mortality. Milbank Memorial Fund Quarterly 45, 31-73 (1967).

21. Kawachi, I., Adler, N. \& Dow, W. H. Money, schooling, and health: Mechanisms and causal evidence. Annals of the New York Academy of Sciences 1186, 56-68 (2010).

22. Strehler, B. L. \& Mildvan, A. S. General theory of mortality and aging. Science 132, 14-21 (1960).

23. Riggs, J. E. The Gompertz function: Distinguishing mathematical from biological limitations. Mechanisms of Ageing and Development 69, 33-36 (1993).

24. Finkelstein, M. Discussing the Strehler-Mildvan model of mortality. Demographic Research 26, 191-206 (2012).

25. Li, T. \& Anderson, J. J. The Strehler-Mildvan correlation from the perspective of a two-process vitality model. Population Studies 69, 91-104 (2015).

26. Yashin, A. I., Begun, A. S., Boiko, S. I., Ukraintseva, S. V. \& Oeppen, J. The new trends in survival improvement require a revision of traditional gerontological concepts. Experimental Gerontology 37, 157-167 (2001).

27. Gavrilov, L. A. \& Gavrilova, N. L. The Biology of Lifespan: A Quantitative Approach. (Harwood Academic, 1991).

28. Gavrilov, L. A. \& Gavrilova, N. S. in Handbook of Models for Human Aging (ed P Michael Conn) 45-68 (Elsevier Academic Press, 2006).

29. Zheng, H., Yang, Y. \& Land, K. Heterogeneity in the Strehler-Mildvan general theory of mortality and aging. Demography 48, 267-290 (2011).

30. Rosenberg, B., Kemeny, G., Smith, L. G., Skurnick, I. D. \& Bandurski, M. J. The kinetics and thermodynamics of death in multicellular organisms. Mechanisms of Ageing and Development 2, 275-293 (1973).

31. Gavrilov, L. A. \& Gavrilova, N. S. in Handbook of Models for Human Aging (eds E. J. Masoro \& S. N. Austad) 3-42 (Academic Press, 2006).

32. Banks, H. T., Banks, J. E. \& Joyner, S. L. Estimation in time-delay modeling of insecticide-induced mortality. CRSC Technical Reports, CRSC-TR08-15 (2008).

33. Amal, Y. \& Pinto, M. C. Global solutions for an age-dependent model of nucleation, growth and ageing with hysteresis. Discrete and Continuous Dynamical Systems - B 13, 517 - 535 (2010).

34. Takeuchi, K. A. Scaling of hysteresis loops at phase transitions into a quasiabsorbing state. Physical Review E 77, 1-4, doi:http://dx.doi.org/10.1103/PhysRevE.77.030103 (2008).

35. Aristotle. The Complete Works of Aristotle. (Princeton University Press, [Fourth Century BCE] 1984).

36. Horn, L. R. Contradiction. The Stanford Encyclopedia of Philosophy, http://plato.stanford.edu/entries/contradiction/ accessed May 15. (2015).

37. Wikipedia. Law of thought. Wikipedia, the free encyclopedia http://en.wikipedia.org/wiki/. Accessed December 3. (2015).

38. ESO. European Southern Observatory, "Charting the slow death of the universe." www.eso.org/public/usa/news/eso1533/ Accessed August 18. (2015). 
39. Wikipedia. Entry on "ultimate fate of the universe." Wikipedia, The Free Encyclopedia http://en.wikipedia.org/wiki/. Accessed August 18. (2015).

40. Wikipedia. Global catastrophic risk. Wikipedia, The Free Encyclopedia http://en.wikipedia.org/wiki/. Accessed June 3. (2016).

41. Wikipedia. End time. Wikipedia, The Free Encyclopedia http://en.wikipedia.org/wiki/. Accessed June 3. (2016).

42. Malthus, T. R. An Essay on the Principle of Population. (Cambridge University Press, [1798] 1992).

43. Coleman, D. in The State of Population Theory: Forward from Malthus (eds David Coleman \& Roger Schofield) 14-41 (Basil Blackwell, 1986).

44. Lee, R. D. Population dynamics of humans and other animals. Demography 24, 443-465 (1987).

45. Sinclair, A. R. E. in Ecological Concepts: The Contribution of Ecology to an Understanding of the Natural World (ed J. M. Cherrett) 197-241 (Blackwell, 1988).

46. Sibly, R. M., Barker, D., Denham, M. C., Hone, J. \& Pagel, M. On the regulation of populations of mammals, birds, fish, and insects. Science 309, 607-610 (2005).

47. Belbas, S. A. in The Science of Hysteresis (eds Giorgio Bertotti \& Isaak Mayergoyz) 605-638 (Elsevier, 2006).

48. Carnes, B. A. What is lifespan regulation and why does it exist? Biogerontology 12, 367-374 (2011).

49. Koshland, D. E. Protein shape and biological control. Scientific American 229, 52 64 (1973).

50. Tanner, R. D. \& DeAngelis, L. H. Sigmoidal and growth rate kinetic hysteresis in biochemical systems. The Chemical Engineering Journal 8, 113-123 (1974).

51. Wang, R. R. Yinyang : The Way of Heaven and Earth in Chinese Thought and Culture. Vol. 11 (Cambridge University Press, 2012).

52. Nāgārjuna, A. The Philosophy of the Middle Way: Mūlamadhyamakakārikāa. (State University of New York Press, 1986).

53. Wikipedia. Entry on "Unity of opposites." Wikipedia, The Free Encyclopedia http://en.wikipedia.org/wiki/. Accessed December 4. (2015).

54. Hegel, G. W. F. Vorlesungen über die Logik. (Meiner, [1831] 2001).

55. Heidegger, M. Sein und Zeit. (Max Niemeyer, [1927] 1963).

56. Eliade, M. in Religious Encounters With Death: Insights from the History and Anthropology of Religions (eds Frank E. Reynolds \& Earle H. Waugh) 13-23 (The Pennsylvania State University Press, 1977).

57. Johnston, M. Surviving Death. (Princeton University Press, 2010).

58. Reynolds, F. E. \& Waugh, E. H. Religious Encounters with Death. (The Pennsylvania State University Press, 1977).

59. Wikipedia. Entry on "Heraclitus." Wikipedia, The Free Encyclopedia http://en.wikipedia.org/wiki/. Accessed May 3 (2015).

60. Freud, S. Beyond the Pleasure Principle. (International Psycho-Analytical, 1922).

61. Freud, S. Civilization and Its Discontents. (Hogarth Press, 1930).

62. Wikipedia. Entries on "Death drive" and "Thanatos." Wikipedia, The Free Encyclopedia http://en.wikipedia.org/wiki/. Accessed September 11. (2015).

63. Brown, N. O. Life Against Death: The Psychoanalytical Meaning of History. (Vintage Books, 1959). 
64. Schrödinger, E. Die gegenwärtige Situation in der Quantenmechanik. Naturwissenschaften 23, 807-812; 823-828; 844-849 (1935).

65. Deutsch, D. \& Ekert, A. Beyond the quantum horizon. Scientific American 307, 8489 (2012).

66. Lévi-Strauss, C. Anthropolgie Structurale. (Plon, 1958).

67. Wikipedia. Entry on "Structuralism." Wikipedia, The Free Encyclopedia http://en.wikipedia.org/wiki/. Accessed September 11. (2015).

68. de Coppet, D. 1, 4, 8; 9, 7. La monnaie; Presence de morts et mesure du temps. L'Homme 10, 17-39 (1970).

69. Benecke, M. Eternal Life: Biomedicine, Aging, and Immortality. (Columbia University Press, 2002).

70. Villarreal, L. P. Are viruses alive? Scientific American 291, 101-105 (2004).

71. Rasmussen, S. et al. Protocells: Bridging Non-living and Living Matter. (MIT Press, 2009).

72. Joyce, J. Dubliners. (Garland, [1907] 1993).

73. Neruda, P. Residencia en la Tierra. (Ediciones del Árbol, 1935).

74. Pearson, K. The Chances of Death and Other Studies in Evolution. (Arnold, 1897).

75. Saramago, J. All the Names. (Harcourt, [1997] 1999).

76. Strehler, B. L. Time, Cells, and Aging. (Academic Press, 1977).

77. Turner, E. L. \& Hanley, J. A. Cultural imagery and statistical models of the force of mortality: Addison, Gompertz and Pearson. Journal of the Royal Statistical Society: Series A (Statistics in Society) 173, 483-499 (2010).

78. Kirkwood, T. B. L. in Handbook of the Biology of Aging (eds C. E. Finch \& E. L. Schneider) 27-43 (Reinhold, 1985).

79. Carnes, B. A., Olshansky, S. J. \& Grahn, D. Continuing the search for a law of mortality. Population and Development Review 22, 231-264 (1996).

80. Carnes, B. A., Holden, L. R., Olshansky, S. J., Witten, M. T. \& Siegel, J. S. Mortality partitions and their relevance to research on senescence. Biogerontology 7, 183-198, doi:doi:10.1007/s10522-006-9020-3 (2006).

81. Carnes, B. A. \& Witten, T. M. How long must humans live? The Journals of Gerontology Series A: Biological Sciences and Medical Sciences 69, 965-970, doi:10.1093/gerona/glt164 (2014).

82. Olshansky, S. J. The law of mortality revisited: Interspecies comparisons of mortality. Journal of Comparative Pathology 142, S4-S9 (2010).

83. Li, T. \& Anderson, J. Shaping human mortality patterns through intrinsic and extrinsic vitality processes. Demographic Research 28, 341-372 (2013).

84. Stearns, S. C. The evolution of life histories. (Oxford University Press, 1992).

85. Stearns, S. C., Ackermann, M., Doebeli, M. \& Kaiser, M. Experimental evolution of aging, growth, and reproduction in fruitflies. Proceedings of the National Academy of Sciences 97, 3309-3313 (2000).

86. Monaghan, P., Chamantier, A., Nussey, D. H. \& Ricklefs, R. E. The evolutionary ecology of senescence. Functional Ecology 22, 371-378 (2008).

87. Reznick, D. N., Bryant, M. J., Roff, D. A., Ghalambor, C. K. \& Ghalambor, D. E. Effects of extrinsic mortality on the evolution of senescence in guppies. Nature $\mathbf{4 3 1}$, 1095-1099 (2004). 
88. Ricklefs, R. E. Evolutionary theories of aging: confirmation of a fundamental prediction, with implications for the genetic basis and evolution of life span. The American Naturalist 152, 24-44 (1998).

89. Ricklefs, R. E. Life-history connections to rates of aging in terrestrial vertebrates. Proceedings of the National Academy of Sciences 107, 10314-10319, doi:10.1073/pnas.1005862107 (2010).

90. Ricklefs, R. E. \& Scheuerlein, A. Comparison of aging-related mortality among birds and mammals. Experimental gerontology 36, 845-857 (2001).

91. Williams, P. D. \& Day, T. Antagonistic pleiotropy, mortality source interactions, and the evolutionary theory of senescence. Evolution 57, 1478-1488 (2003).

92. Robertson, T. \& Atkins, P. Essential vs. accidental properties, The Stanford Encyclopedia of Philosophy, http://plato.stanford.edu/entries/contradiction/ accessed May 15. (2015).

93. Vaupel, J. W., Manton, K. G. \& Stallard, E. The impact of heterogeneity in individual frailty on the dynamics of mortality. Demography 16, 439-454 (1979).

94. Duchateau, L. \& Janssen, P. The Frailty Model. (Springer, 2008).

95. Rockwood, K. \& Mitnitski, A. Frailty in relation to the accumulation of deficits. The Journals of Gerontology Series A: Biological Sciences and Medical Sciences 62, 722-727 (2007).

96. Mohler, M. J., Fain, M. J., Wertheimer, A. M., Najafi, B. \& Nikolich-Augich, J. The Frailty Syndrome: Clinical measurements and basic underpinnings in humans and animals. Experimental Gerontology 54, 6-13 (2014).

97. Bergman, H. et al. Frailty: An emerging research and clinical paradigm: Issues and controversies. The Journals of Gerontology Series A: Biological Sciences and Medical Sciences 62, 731-737 (2007).

98. Mitnitski, A., Song, X. \& Rockwood, K. Assessing biological aging: the origin of deficit accumulation. Biogerontology 14, 709-717 (2013).

99. Kirkwood, T. B. L. Evolution of ageing. Nature 270, 301-304 (1977).

100. Medawar, P. B. in The Uniqueness of the Individual (ed P. B. Medawar) 44-70 (Methuen, [1952] 1957).

101. Milne, E. M. G. The natural distribution of survival. Journal of Theoretical Biology 255, 223-236 (2008).

102. Munch, S. B. \& Mangel, M. Evaluation of mortality trajectories in evolutionary biodemography. Proceedings of the National Academy of Sciences 103, 1660416607, doi:10.1073/pnas.0601735103 (2006).

103. Szilard, L. On the nature of the aging process. Proceedings of the National Academy of Sciences 45, 30-45 (1959).

104. Wikipedia. Thanatos. Wikipedia, the free encyclopedia http://en.wikipedia.org/wiki/. Accessed December 3 (2015).

105. Wikipedia. Bhagavad Gita. Wikipedia, the free encyclopedia http://en.wikipedia.org/wiki/. Accessed December 3 (2015).

106. Hijiya, J. A. The Gita of J. Robert Oppenheimer. Proceedings of the American Philosophical Society 144, 123-167 (2000).

107. Mathers, C. D. \& Loncar, D. Projections of global mortality and burden of disease from 2002 to 2030. Plos Medicine (2006).

108. WHO. International Classification of Diseases. http://www.who.int/classifications/icd/en/. Accessed 2013 March 12 (2013). 
109. Spinoza, B. Opera Posthuma. (Quodlibet, [1677] 2008).

110. Bergson, H. L'évolution créatice. (F. Alcan, 1907).

111. Wikipedia. Entries on "conatus," "élan vital,"and "selfish gene." Wikipedia, The Free Encyclopedia http://en.wikipedia.org/wiki/. Accessed May 3 (2015).

112. Dawkins, R. The selfish gene. (Oxford University Press, [1976] 2006).

113. Wikipedia. Entry on "Antibody." Wikipedia, The Free Encyclopedia http://en.wikipedia.org/wiki/. Accessed May 3 (2015).

114. Wikipedia. Entry on "Selfish gene." Wikipedia, The Free Encyclopedia http://en.wikipedia.org/wiki/. Accessed May 3 (2015).

115. Pearl, R. The Rate of Living. (Alfred A. Knopf, 1928).

116. Anderson, J. J. in Individual-based models and approaches in ecology (eds D. L. DeAngelis \& L.J. Gross) 256-277 (Chapman \& Hall, 1992).

117. Anderson, J. J. Vitality-based model relating stressors and environmental properties to organism survival. Ecological Monographs 70, 445-470. (2000).

118. Anderson, J. J., Gildea, M. C., Williams, D. W. \& Li, T. Linking growth, survival, and heterogeneity through vitality. The American Naturalist 171, E20-E43 (2008).

119. Anderson, J. J. \& Li, T. A two-process mortality model with extensions to juvenile mortality, population dynamics, and evolution. Population Association of America Meeting (2015).

120. Li, T. \& Anderson, J. J. The vitality model: A way to understand population survival and demographic heterogeneity. Theoretical Population Biology 76, 118131 (2009).

121. Zuev, S. M. et al. Vitality index in survival modeling: how physiological aging influences mortality. Journal of Gerontology A 55, B10-19 (2000).

122. Wikipedia. Elixir of life. Wikipedia, the free encyclopedia http://en.wikipedia.org/wiki/. Accessed December 3 (2015).

123. Epelbaum, M. Lifespan and aggregate size variables in specifications of mortality or survivorship. PLoS ONE 9, e84156 (2014).

124. Kuhn, T. S. The structure of scientific revolutions. Second edn, (University of Chicago Press, [1962] 1970).

125. Schickore, J. Scientific discovery. Stanford Encyclopedia of Philosophy, http://plato.stanford.edu/entries/scientific-discovery/ (2014).

126. Granger, C. W. Testing for causality: A personal viewpoint. Journal of Economic Dynamics and Control 2, 329-352 (1980).

127. Heckman, J. J. The scientific model of causality. Sociological Methodology 35, 197 (2005).

128. Kleinberg, S. Causality, probability, and time. (Cambridge University Press, 2013).

129. Kleinberg, S. Why: A guide to finding and using causes. (O'Reilly Media, 2015).

130. Pearl, J. Causality: Models, Reasoning and Inference. Second edn, (Cambridge University Press., 2009).

131. Hill, A. B. The environment and disease: Association or causation? Proceedings of the Royal Society of Medicine 58, 295-300 (1965).

132. Kleinberg, S. \& Hripcsak, G. A review of causal inference for biomedical informatics. Journal of Biomedical Informatics 44, 1102-1112 (2011).

133. Krieger, N. Epidemiology and the web of causation: has anyone seen the spider? Social Science \& Medicine 39, 887-903 (1994). 
134. Krieger, N. Proximal, distal, and the politics of causation: What's level got to do with it? American Journal of Public Health 98, 221-230 (2008).

135. Ward, A. Causal criteria and the problem of complex causation. Medicine, Health Care and Philosophy 12, 333-343 (2009).

136. Ward, A. The role of causal criteria in causal inferences: Bradford Hill's "aspects of association". Epidemiologic Perspectives \& Innovations 6, 2 (2009).

137. Kaplan, G. A. What's wrong with social epidemiology, and how can we make it better? Epidemiologic Reviews 26, 124-135 (2004).

138. Rothman, K. J., Greenland, S., Poole, C. \& Lash, T. L. in Modern Epidemiology (eds Kenneth J. Rothman, Sander Greenland, Charles Poole, \& Timothy. L. Lash) 6-31 (Lippincott, Williams and Wilkins, 2008).

139. Kahneman, D. \& Tversky, A. Prospect theory: An analysis of decision under risk. Econometrica 47, 263-291 (1979).

140. Tversky, A. \& Kahneman, D. The framing of decisions and the psychology of choice. Science 211, 453-458 (1981).

141. Wikipedia. Entry on "survivorship bias," http://en.wikipedia.org/wiki/. Accessed on January 5. (2014).

142. Olivola, C. Y. \& Sagara, N. Distributions of observed death tolls govern sensitivity to human fatalities. Proceedings of the National Academy of Sciences 106, 2215122156, doi:10.1073/pnas.0908980106 (2009).

143. Elton, E. J., Gruber, M. J. \& Blake, C. R. Survivor bias and mutual fund performance. Review of Financial Studies 9, 1097-1120, doi:10.1093/rfs/9.4.1097 (1996).

144. Ioannidis, J. P. A. Why Most Published Research Findings Are False. PLoS Med 2, e124 (2005).

145. Chomsky, N. Syntactic Structure. (Mouton, 1957).

146. de Saussure, F. Cours de Linguistique Générale. (Payot, 1916).

147. Wikipedia. Entry on "Deep structure and surface structure" Wikipedia, The Free Encyclopedia http://en.wikipedia.org/wiki/. Accessed September 11. (2015).

148. Bollen, K. A. Structural Equations with Latent Variables. (Wiley, 1989).

149. Bollen, K. A. Latent variables in psychology and the social sciences. Annual Review of Psychology 53, 605-634 (2002).

150. Maybee, J. E. Hegel's dialectics. The Stanford Encyclopedia of Philosophy, http://plato.stanford.edu/archives/sum2016/entries/hegel-dialectics (2016).

151. Wikipedia. Aufheben. Wikipedia, the free encyclopedia http://en.wikipedia.org/wiki/. Accessed July 29 (2016).

152. Gompertz, B. On the nature of the function expressive of the law of human mortality, and on a new mode of determining the value of life contingencies. Philosophical Transactions of the Royal Society of London 115, 513-585 (1825).

153. Makeham, W. M. On the law of mortality and the construction of annuity tables. Journal of the Institute of Actuaries and Assurance 13, 325-367 (1867).

154. Yashin, A. I., Iachine, I. A. \& Begun, A. S. Mortality modeling: A review. Mathematical Population Studies 8, 305-332 (2000).

155. Bebbington, M., Lai, C.-D. \& Zitikis, R. A. Modelling deceleration in senescent mortality. Mathematical Population Studies 18, 18-37 (2011). 
156. Juckett, D. A. \& Rosenberg, B. Comparison of the Gompertz and Weibull functions as descriptors for human mortality distributions and their intersections. Mechanisms of Ageing and Development 69, 1-31 (1993).

157. Olshansky, S. J. \& Carnes, B. A. Ever since Gompertz. Demography 34, 1-15 (1997).

158. Smith, D. \& Keyfitz, N. Mathematical Demography. (Springer-Verlag, 1977).

159. Corbaux, F. On the Natural and Mathematical Laws Concerning Population, Vitality, and Mortality. (W. Wilson, 1833).

160. Azbel', M. Y. Universal biological scaling and mortality. Proceedings of the National Academy of Sciences 91, 12453-12457 (1994).

161. Azbel', M. Y. Conservation laws of metabolism and mortality. Physica A: Statistical Mechanics and its Applications 329, 436-450 (2003).

162. Horiuchi, S. in Life Span: Evolutionary, Ecological, and Demographic Perspectives (eds James R. Carey \& Shripad Tuljapurkar) 127-151 (Population Council, 2003).

163. Beard, R. E. in Ciba Foundation Colloquia on Ageing. Volume V: The Lifespan of Animals Vol. 5 (eds G.E.W. Wolstenholme \& Margaret P. Cameron) 302-311 (Little, Brown, 1959).

164. Graunt, J. Natural and Political Observations Mentioned in a Following Index, and Made Upon the Bills of Mortality. (Roycroft, 1662).

165. Halley, E. An estimate of the degrees of the mortality of mankind, drawn from curious tables of the births and funerals at the city of Breslaw; with an attempt to ascertain the price of annuities upon lives. Philosophical Transactions of the Royal Society of London 17, 596-610 (1693).

166. Heligman, L. \& Pollard, J. H. The age pattern of mortality. Journal of the Institute of Actuaries 107, 49-80, doi:doi:10.1017/S0020268100040257 (1980).

167. Weon, B. M. \& Je, J. H. Trends in the scale and shape of survival curves. Scientific Reports 2, 504, doi:DOI: 10.1038/srep00504 (2012).

168. Mueller, L. D., Rauser, C. L. \& Rose, M. R. Does Aging Stop? , (Oxford University Press, 2011).

169. Witten, T. M. \& Eakin, T. Multiphasic models of survival: Background and early developments. Experimental Gerontology 32, 259-285 (1997).

170. Chu, C. Y. C., Chien, H.-K. \& Lee, R. D. Explaining the optimality of U-shaped age-specific mortality. Theoretical Population Biology 73, 171-180 (2008).

171. Wood, J. W., Holman, D. J., O'Connor, K. A. \& Ferrell, R. J. Mortality models for paleodemography. Cambridge studies in biological and evolutionary anthropology, 129-168 (2002).

172. Jones, O. R. et al. Diversity of ageing across the tree of life. Nature 505, 169 - 173 (2014).

173. Krakauer, D. C. et al. The challenges and scope of theoretical biology. Journal of Theoretical Biology 276, 269-276 (2011).

174. Walker, H. A. \& Cohen, B. P. Scope statements: Imperatives for evaluating theory. American Sociological Review 50, 288-301 (1985). 